\title{
Characterization of a novel aspartyl protease inhibitor from Haemonchus contortus
}

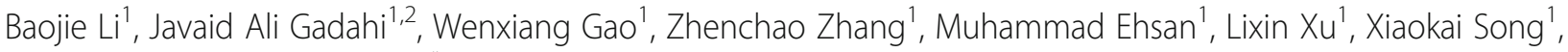
Xiangrui $\mathrm{Li}^{1}$ and Ruofeng Yan ${ }^{1 *}$

\begin{abstract}
Background: Aspartyl protease inhibitor (API) was thought to protect intestinal parasitic nematodes from their hostile proteolytic environment. Studies on Ostertagia ostertagi, Ascaris suum and Brugia malayi indicated that aspins might play roles in nematode infection. In a recent study, proteins differentially expressed between free-living third-stage larvae (L3) and activated L3 (XL3) of Haemonchus contortus were identified by 2D-DIGE. API was found downregulated in $x \mathrm{~L} 3$ when compared with $\mathrm{L} 3$. However, there was no report about the functions of $\mathrm{H}$. contortus API in the parasitehost interaction. In this study, the gene encoding API from H. contortus was cloned, expressed, and part of its biological characteristics were studied.

Results: A DNA fragment of 681 bp was amplified by RT-PCR. Ninety one percent of the amino acid sequence was similar with that for aspin from 0 . ostertagi. The recombinant API protein was fusion-expressed with a molecular weight of $48 \times 10^{3}$. Results of Western blot showed that the recombinant API could be recognized by serum from goat infected with $\mathrm{H}$. contortus. It was found that API was localized exclusively in the subcutaneous tissue and epithelial cells of the gastrointestinal tract in adult $H$. contortus. qRT-PCR suggested that the API gene was differentially transcribed in different life-cycle stages, with the lowest level in female adults and the highest in free-living L3 larvae. Enzyme inhibition assay indicated that the recombinant API can inhibit the activity of pepsin significantly, and the optimal reaction pH and temperature were 4.0 and $37-50{ }^{\circ} \mathrm{C}$ respectively. In vitro study showed that the recombinant API could induce goat PBMCs to express IFN- $\gamma$, IL-4 and IL-10.
\end{abstract}

Conclusions: A new aspartyl protease inhibitor was cloned from $\mathrm{H}$. contortus and its characteristics were studied for the first time. The results indicate that API may regulate the immune response of the host and play roles in the infection.

Keywords: Haemonchus contortus, Aspartyl protease inhibitor, Localization, Differential expression, Inhibitory activity, Induction of cytokines

\section{Background}

Haemonchus contortus is one of the most important gastrointestinal parasitic nematodes infecting the abomasum of ruminants worldwide, especially sheep, goats and cattle [1]. This nematode feeds on blood and often causes local damage, anemia, and significant production losses, even death in young and weakened hosts, which results in huge economic losses to the livestock industry $[2,3]$. This

\footnotetext{
* Correspondence: yanruofeng@njau.edu.cn

'College of Veterinary Medicine, Nanjing Agricultural University, Nanjing 210095, People's Republic of China

Full list of author information is available at the end of the article
}

parasite has a life-cycle consisting of free-living stages on pasture (from eggs to L3 larvae) and after ingestion, development through L4 larva to adult in the host gastrointestinal tract $[4,5]$. Controlling of $H$. contortus is almost depending on the use of anthelmintics. The growing emergence of resistant strains of $H$. contortus has resulted in the need to find new ways to prevent and control this parasite. So far, only one commercial vaccine was used in prevention the infection with this parasite [6]. More work should be done on exploring new antigens and further study needed on the biological characteristics of the known proteins [7-9]. 
Aspartyl protease inhibitors (API) are thought to protect intestinal parasitic nematodes from their hostile proteolytic environment; their presence could explain the resistance of the parasite to the digestive enzymes of the host [10]. In free-living life-cycle stages of parasitic or non-parasitic nematodes, API can also regulate endogenously secreted proteases [11]. Aspins from Ostertagia ostertagi [10], Ascaris suum [12], Brugia malayi [13] and Parelaphostrongylus tenuis [14] were found to be important in nematode infection.

In a recent research, proteins extracted from L3 and activated L3 (xL3) of $H$. contortus were analyzed by comparative proteomics. One hundred and twenty four protein spots were found to be differentially expressed. In that study, aspartyl protease inhibitor was identified and was found to be downregulated in xL3 when compared with free-living L3 [15]. However, the functions of this protein were not clear. In the present study, the gene encoding $H$. contortus was cloned and part of the biological characters of this protein was studied for the first time.

\section{Methods}

\section{Animals, parasites and cells}

Local 3-6 month-old goats were housed indoors and dewormed twice at 2 weekly intervals with levamisole ( $8 \mathrm{mg} / \mathrm{kg}$ body weight). Fecal sample from each goat was examined by microscopy for helminth eggs after 2 weeks. The animals excreting no eggs were used in the subsequent study.

SD rats (body weight $\sim 150 \mathrm{~g}$ ) were purchased from the Experimental Animal Center of Jiangsu, P. R. China (Qualified Certificate: SCXK 2008-0004). The animals were raised in a sterilized room and fed sterilized food and water.

Haemonchus contortus strain was kept in the laboratory of veterinary parasitology, Nanjing Agricultural University. Worms were maintained by serial passage in helminth-free goats as described before [16]. The procedures of collection and preservation of eggs, L3, xL3 and male and female adults of $H$. contortus were performed as described previously [17]. The isolation and culture of goat PBMCs were performed as described in [18].

\section{Cloning and sequence analysis of $A P I$ gene}

Total RNA was isolated from $H$. contortus adults. The DNA fragment encoding API was amplified by RT-PCR, with a pair of gene-specific primers. For the subsequent cloning, two enzyme restriction sites (BamHI and HindIII) were added at the $5^{\prime}$-end of the primers. The sequences of these primers are listed in Additional file 1: Table S1. After RT-PCR amplification, the products were purified by $1 \%$ agarose gel electrophoresis and cloned into pMD18-T vector (TaKaRa, Daliang, China). The recombinant plasmid pMD-18/API was transformed into Escherichia coli strain DH5 $\alpha$, cultured in Luria Bertini medium (LB) with ampicillin $(100 \mu \mathrm{g} / \mathrm{ml})$. The API gene was validated by sequence analyzing, and comparing online using the Blast program (http://www.ncbi.nlm.nih.gov).

\section{Expression and purification of recombinant API protein}

The identified recombinant plasmids pMD-18/API was digested with restriction enzymes BamHI and HindIII. The target fragment of API was purified and cloned into the pET32a $(+)$ expression plasmid vector digested with the same enzymes. The recombinant plasmid pET32/API was transformed into E. coli strain BL21 (DE3). Positive clones were picked out and cultured in LB with ampicillin $(100 \mu \mathrm{g} / \mathrm{ml})$ at $37{ }^{\circ} \mathrm{C}$ until $\mathrm{OD}_{600}$ achieved 0.6 [19]. Isopropyl-B-D- thiogalactopyranoside (IPTG) was added to the final concentration of $0.8 \mathrm{mM}$ and incubated for another $5 \mathrm{~h}$. To harvest the recombinant protein, the cell pellet was lysed using lysozyme $(10 \mu \mathrm{g} / \mathrm{ml})$ followed by sonication and then the cell lysates were analyzed by $12 \%$ (w/v) SDS-PAGE.

The recombinant API protein was purified by $\mathrm{Ni}^{2+}$-nitrilotriacetic acid (Ni-NTA) column according to the manufacturer's instructions. The purified protein was refolded by renaturation buffer $(20 \mathrm{mmol} / \mathrm{l}$ Tris-Cl, $500 \mathrm{mmol} / \mathrm{l}$ $\mathrm{NaCl}, 1 \mathrm{mmol} / \mathrm{l}$ GSH, $0.1 \mathrm{mmol} / \mathrm{l} \mathrm{GSSG}, \mathrm{pH}$ 8.0) containing different concentrations of urea $(8,6,4,2,0 \mathrm{M})$ [20]. The concentration of refolded protein was determined according to the Bradford procedure [21].

About $0.3 \mathrm{mg}$ of the purified recombinant API protein was mixed with Freund's complete adjuvant as 1:1 mixture and inject into SD rats subcutaneously in multiple places as described by Han et al. [22]. Rats were boosted four times at two weeks intervals with the same dose of recombinant protein mixed with Freund's incomplete adjuvant as 1:1 mixture. The sera against API were collected 10 days after the last immunization and stored at $-80{ }^{\circ} \mathrm{C}$ until use. The serum against $H$. contortus was harvested from naturally infected goat [23].

The recombinant API protein and soluble proteins from $H$. contortus adult worms were separated by $12 \%$ SDS-PAGE, followed by electro-transferred onto a nitrocellulose membranes. After being blocked with $5 \%(\mathrm{w} / \mathrm{v})$ skimmed milk powder in PBST (PBS with $0.5 \%$ Tween-20) at $4{ }^{\circ} \mathrm{C}$ overnight, the membranes were incubating with the first antibody (anti-H. contortus serum from goats or serum against recombinant API from rats) (1:1,000 dilution) for $1 \mathrm{~h}$ at $37^{\circ} \mathrm{C}$. Then, the membrane was washed three times with PBST and incubated with the secondary antibody (rabbit anti goat IgG-HRP or goat anti rat IgG-HRP (Santa Cruz Biotechnology, Dallas, USA) in PBST (1:5,000 dilution) for $1 \mathrm{~h}$ at $37{ }^{\circ} \mathrm{C}$. After three washes, the immunoreaction was visualized using freshly 
prepared diaminobenzidine (DAB, Sigma ImmunoChemicals, Dorset, UK) as a substrate for $5 \mathrm{~min}$.

\section{Localization analysis}

Freshly collected adult male and female $H$. contortus parasites were washed in PBS. The worms were dehydrated and then embedded in TISSUE-TEK ${ }^{\circ}$ O.C.T. compound (SAKURA Finetek, Torrance, USA). They were snap-frozen in liquid nitrogen and stored at $-20{ }^{\circ} \mathrm{C}$ until further processing. Using a cryotome (CM1950, Leica Instruments GmbH, Wetzlar, Germany), $8 \mu \mathrm{m}$ thick sections were cut and mounted on Poly-L-lysine hydrobromide glass slides. The sections were further treated as described previously [17]. Briefly, sections were washed with PBS and blocked with 5\% BSA in PBST for $1 \mathrm{~h}$ at $37{ }^{\circ} \mathrm{C}$ to prevent non-specific binding. Thereafter, the sections were incubated with rat anti-API serum (1:300 dilution) or normal rat serum (negative control) for $1 \mathrm{~h}$ at $37{ }^{\circ} \mathrm{C}$. Following by washing with PBS for 3 times, the sections were incubated with Cy3-labeled Goat Anti-Rat IgG (1:1,000 dilution, Beyotime Institute of Biotechnology, Shanghai, China). After washing with PBS, the sections were immersed with Antifade Mounting Medium (Beyotime Institute of Biotechnology, Shanghai, China) which prevents the fading of fluorescence during microscopic examination.

\section{Differential expressions}

Eggs, L3, xL3, male and female adult $H$. contortus were used for the differential expression of API. Total RNA was extracted and cDNA was reverse-transcribed using a HiScript ${ }^{\circ}$ Q RT SuperMix for qPCR (Vazyme, Nanjing, China) according to the manufacturer's instructions. Real-time PCR was performed on ABI 7500 Real Time PCR System (Applied Biosystems, New York, USA), using the standard procedure. The reactions and conditions of real time PCR are detailed in Additional file 2: Protocols. The primers for real-time PCR are listed in Additional file 1: Table S2. The amplification efficiencies of target and reference genes were verified and the results are shown in Additional file 3: Figure S1. The transcription levels for $A P I$ in different life-cycle stages were analyzed by the ABI Prism 7500 software version 2.0.6 (Applied Biosystems, New York, USA) used the comparative Ct $\left(2^{-\Delta \Delta C t}\right)$ method [24]. This experiment was repeated three times.

\section{Pepsin inhibition assay}

Activity of the recombinant API protein in inhibiting protease (pepsin) was tested as described previously [25]. Fifty micrograms of recombinant API and the same weight of pepsin (Ameresco, Kaysville, USA) were dissolved in $10 \mathrm{mM}$ acetate $(\mathrm{pH} 2.0)$ and incubated for
30 min at $37{ }^{\circ} \mathrm{C}$, the residual enzyme activity of pepsin was determined by Pepsin assay kit (Nanjing Jiancheng Bio, Nanjing, China) according to the manufacturer's instructions. Breifly, $150 \mu \mathrm{g}$ of hemoglobin (Nanjing Jiancheng Bio, Nanjing, China) dissolved in the same buffer, was added to the above reaction and incubated for another $30 \mathrm{~min}$ at $37^{\circ} \mathrm{C}$ and the resulting products were analyzed by $12 \%$ SDS-PAGE. The inhibition efficiencies for API in different reactive $\mathrm{pH}(2-10)$ and temperature $\left(37-100{ }^{\circ} \mathrm{C}\right)$ were also checked. Trypsin (Ameresco, Kaysville, USA) was chosen as a control in this study. Each experiment was run in triplicate.

\section{Cytokine expressions in vitro}

Effects of the recombinant API on the cytokine expression were evaluated. For that purpose goat PBMCs $\left(1 \times 10^{8}\right)$ were incubated with 10,20 and $40 \mu \mathrm{g}$ of recombinant API or vehicle (PBS, negative control) for $12 \mathrm{~h}$. Then, the cells were harvested and total RNA extracted. The transcriptions of $I L-2, I L-4, I L-10, I L-17, I F N-\gamma$ and TGF- $\beta$ were quantified by real time PCR. The reactions and conditions are described in Additional file 2: Protocols. The primers for real time PCR are listed in Additional file 1: Table S3. The amplification efficiencies of target and reference genes were verified and the results were shown in Additional file 3: Figure S2.

\section{Statistical analysis}

In all experiments, data points were plotted using GraphPad Prism 6.0 (GraphPad Software, Inc., San Diego, CA). The data were presented as the mean and standard error of the mean (SEM) of three independent experiments. Real time PCR for cytokine expression analyses were performed using the Student's $t$-test. $P$-value $\leq 0.05$ was considered statistically significant.

\section{Results \\ Cloning and expression of $A P I$ from $\mathrm{H}$. contortus}

The complete coding sequence of API contains $681 \mathrm{bp}$ was cloned from $H$. contortus, which encoded a protein of 226 amino acids with predicted molecular weight about $25 \mathrm{kDa}$ and calculated $\mathrm{pI}$ of 5.95 . The gene sequence was submitted to GenBank under accession number KY284864. The amino acid sequence of this protein was compared with the known aspins; this showed significant homology with aspin sequences from O. ostertagi (GenBank accession no. CAD10783, 91\% identity), T. colubriformis (AY189824, 85\% identity) and C. elegans (AAC46663, 51\% identity).

The alignment of $H$. contortus API with other nematode aspins is presented in Fig. 1. Some structures conserved in the aspin family were found in $H$. contortus API. There are four cysteine residues in the sequence. A predicted cleavage site between residues alanine (15) and 


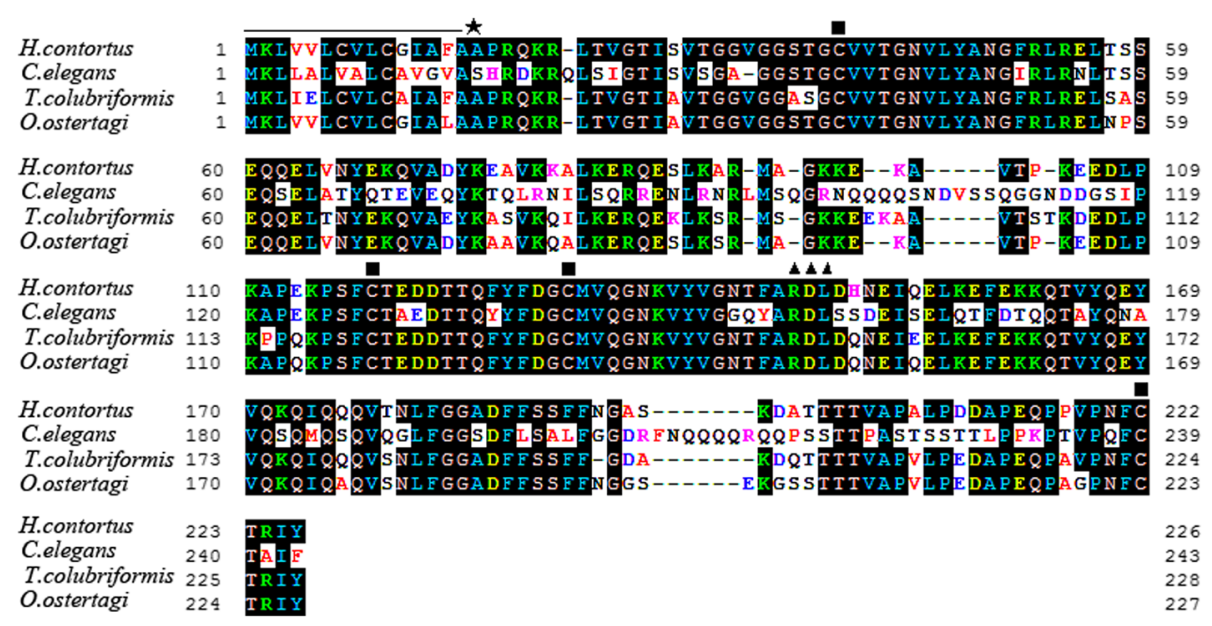

Fig. 1 Alignment of $H$. contortus API with aspins from other nematodes. The amino acid sequence of $H$. contortus API is compared with those from $C$. elegans (AAC46663), T. colubriformis (AY189824) and O. ostertagi (CAD10783). The conserved cysteine residues and cleavage sites are marked by and $\star$. "RDL" motif is indicated by $\boldsymbol{\Lambda}$. Putative signal sequence is overlined

alanine (16) was found at the N-terminal of the protein. The motif "YVRDLT" considered to be the active site of the aspartyl protease inhibitor was also found in this protein.

The recombinant API was expressed as a fusion protein with the molecular weight of $43 \mathrm{kDa}$. The target protein was purified from the cell supernatants as well as inclusion body (Fig. 2, Lanes 1 and 2). Western blot showed that the recombinant API could be recognized by serum from goats infected with $H$. contortus, and the native API protein from $H$. contortus could be recognized by antibody against recombinant API (Fig. 2, Lanes 3 and 5). No protein was recognized by the normal serum (Fig. 2, Lanes 4 and 6).

\section{Localization of API}

Immunohistochemical test was performed to find out the native HcAPI localization site within the worms. Red specific fluorescence was detected on the internal surface and the gut of worms in the sections of both female and male adult $H$. contortus, whereas no red fluorescence was observed in controls (Fig. 3).

\section{Differential expression of $A P I$}

The results of real time PCR indicated that transcriptions of $A P I$ were significantly different in the eggs, L3, xL3, adult male and female of $H$. contortus (Fig. 4). The highest expression of $A P I$ was found in the free living stage (L3). When L3 was activated and turned into parasitic stage $\mathrm{xL} 3$, the expressions were downregulated, and the expression levels continuously decreased in the adults.

\section{Pepsin inhibition assay}

As shown in Fig. 5, the inhibition activity of the recombinant API was measured. The activity of pepsin in hemoglobin digestion declined significantly when compared with the control (Lanes 4 and 5). However, the activity of trypsin in BSA digestion was not inhibited by this recombinant API (Lanes 8 and 9). To quantitate the

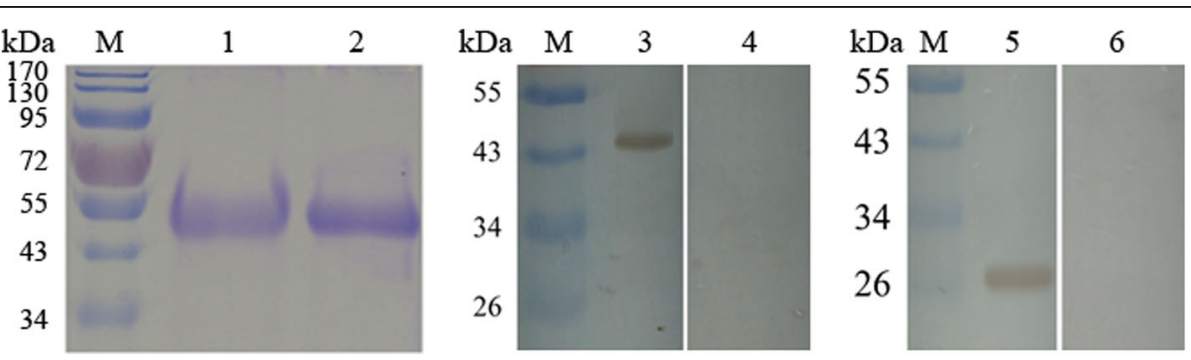

Fig. 2 Purification of recombinant API protein and western blot. Recombinant API from the supernatants (Lane 1) and the inclusion body (Lane 2) of the bacterial cells were purified and separated by SDS-PAGE. Recombinant API was detected by serum from goat infected with H. contortus (Lane 3), and normal goat serum as negative control (Lane 4). API extracted from $\mathrm{H}$. contortus was detected by rat antibody against recombinant API protein (Lane 5), and normal rat serum as negative control (Lane 6). Lane M: pre-stained protein ladder 


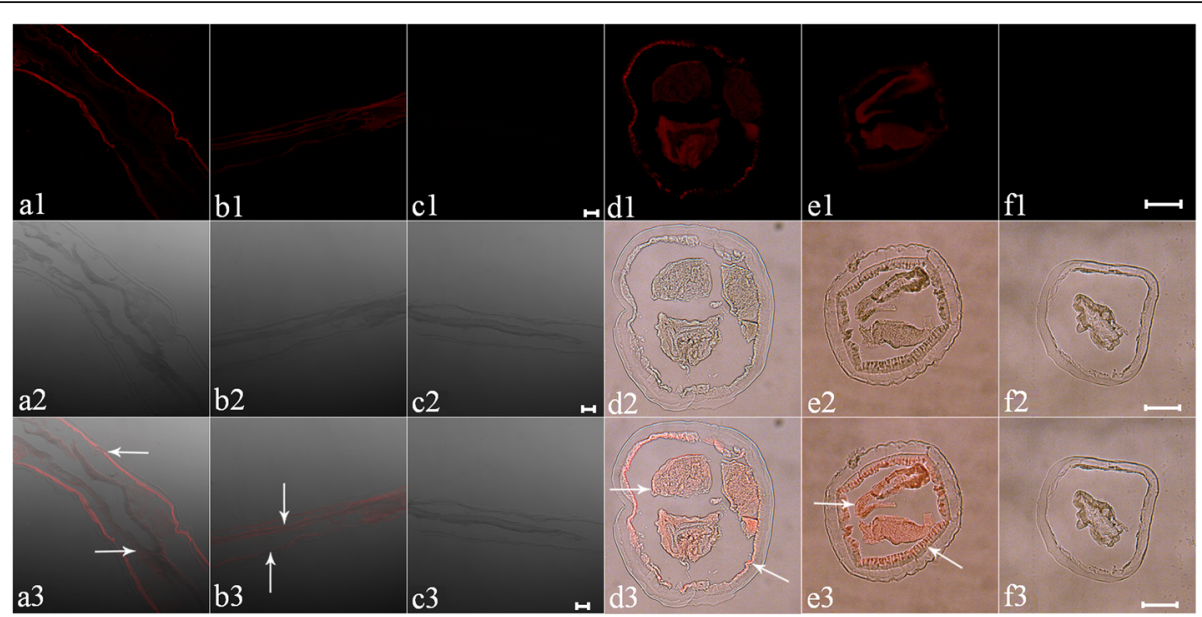

Fig. 3 Localization of API in adult worms. Cryostal sections of H. contortus were incubated with rat antibody against the recombinant API, following with the second antibody Cy3-labeled Goat Anti-Rat IgG. The red fluorescence was detected in both female $(\mathbf{a}, \mathbf{d})$ and male $(\mathbf{b}, \mathbf{e})$ adult $H$. contortus, but no fluorescence was observed in control experiments $(\mathbf{c}, \mathbf{f})$. To see the distributions of the API, vertical $(\mathbf{a}, \mathbf{b}, \mathbf{c})$ and transverse sections $(\mathbf{d}$, e, $\mathbf{f})$ were checked. Images in lines 1 and 2 were taken under UV light and white field; merged images are given in line 3. Scale-bars: $100 \mu \mathrm{m}$

inhibition effects of the recombinant API, a pepsin assay kit was used. The results showed that the activity of pepsin was decreased by $63 \%$ when compared with the negative control (without adding the recombinant API). It was found that the recombinant API showed the best inhibition effects at the $\mathrm{pH}$ of 4.0 (Fig. 6a) at $37-50{ }^{\circ} \mathrm{C}$ (Fig. 6b). The recombinant API also showed partial inhibition activities (relative

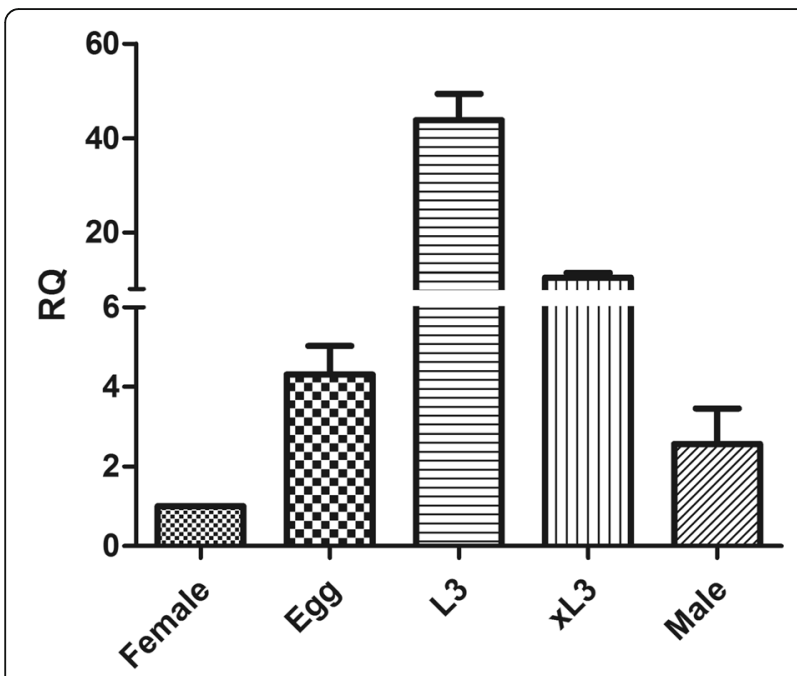

Fig. 4 Expression patterns of $A P I$ in different life stages of $H$. contortus. Expression levels of $A P I$ mRNA in egg, $L 3, x L 3$, adult male and female were tested by real time PCR. The relative quantities $(R Q$, compared with female adult worm, female $=1$ ) in egg, $L 3, x L 3$ and adult male were $4.3,43.8,10.5$ and 2.6 , respectively. The value of API gene in the female was normalized to 1.0. The relative changes in gene expression ratios of selected genes were normalized to the expression of a single reference gene and calculated as described by the $2^{-\Delta \Delta C t}$ method. Error bars indicate SEM from three independent experiments inhibitory rate $>50 \%$ ) under $\mathrm{pH}$ between 2.0 and 8.0 (Fig. 6a). The recombinant API protein kept stable at temperatures between 37 and $80{ }^{\circ} \mathrm{C}$ (Fig. 6b).

\section{Effects on cytokine expression by goat PBMCs}

PBMCs consist of several populations of $\mathrm{T}$ cells, $\mathrm{B}$ cells, NK cells and other monocytes that play important roles in the immune responses. In the present study, in vitro effects of the recombinant API protein on the cytokine expression in PBMCs were evaluated. Result of transcription levels of $I L-2$, $I L-4, I L-10, I L-17, I F N-\gamma$ and $T G F-\beta$ are shown in Fig. 7. After incubation with the recombinant API,

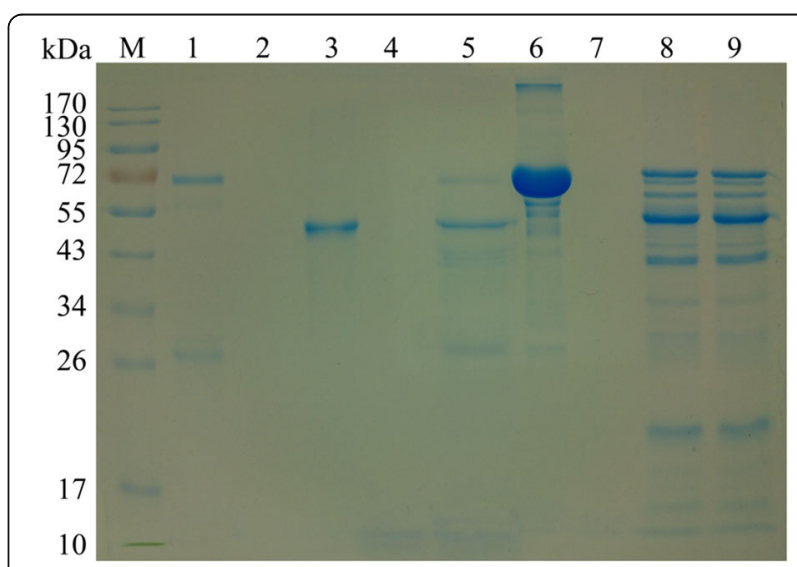

Fig. 5 Inhibition assay of API on pepsin and trypsin. The products of hemoglobin (BSA) digested by pepsin (trypsin) with (or without) API were analysed by SDS-PAGE. Lane 1: hemoglobin; Lane 2: pepsin; Lane 3: API; Lane 4: pepsin + hemoglobin; Lane 5, pepsin incubated with API for 30 min (at $37^{\circ} \mathrm{C}, \mathrm{pH}$ 4.0) + hemoglobin; Lane 6: BSA; Lane 7: trypsin; Lane 8: trypsin + BSA; Lane 9: trypsin incubated with API for 30 min (at $37^{\circ} \mathrm{C}, \mathrm{pH} 4.0$ ) + BSA 

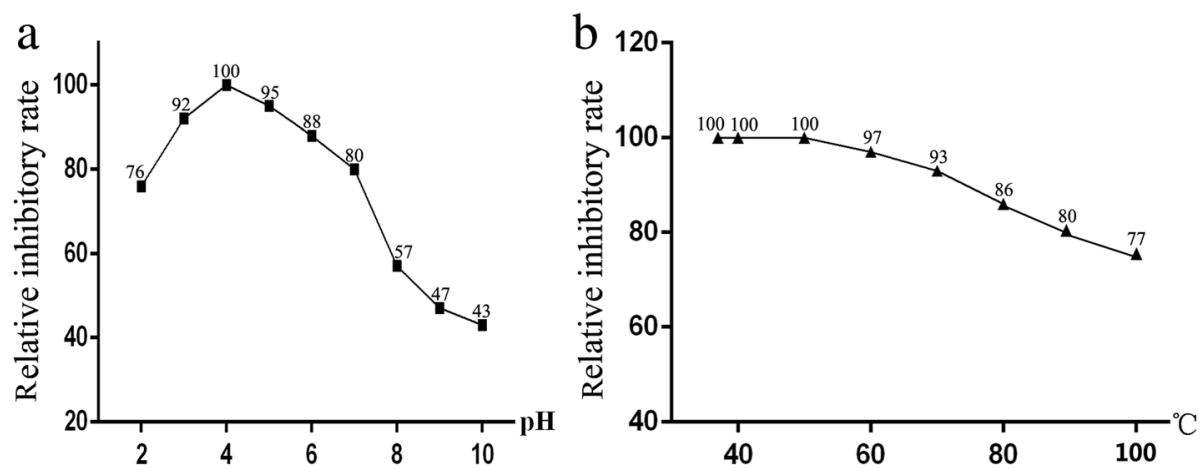

Fig. 6 Effects of $\mathrm{pH}$ value and temperature on the inhibition activities of recombinant API. Recombinant API was dissolved in the buffer with a serial $\mathrm{pH}$ value from 2 to 10 for $30 \mathrm{~min}(\mathbf{a})$, or treated at temperatures between 37 and $100{ }^{\circ} \mathrm{C}(\mathbf{b})$. The result API was added to the reaction with Pepsin and hemoglobin, and the relative inhibitory rate was tested by pepsin assay kit. The inhibition activity was defined as 100 when the reaction was carried out under $\mathrm{pH} 4.0$ at $37^{\circ} \mathrm{C}$

the expressions of IFN- $\gamma\left(t_{(4)}=13.74, P=0.0048\right), I L-4$ $\left(t_{(4)}=5.17, P=0.034\right)$ and $I L-10 \quad\left(t_{(4)}=4.35, P=0.048\right)$ increased significantly, while those of $I L-2\left(t_{(4)}=1.55\right.$, $P=0.26), I L-17\left(t_{(4)}=1.36, P=0.30\right)$ and TGF- $\beta\left(t_{(4)}=\right.$ 2.11, $P=0.12$ ) were not significantly different.

\section{Discussion}

Protease inhibitors have been isolated from a number of parasitic nematodes [26, 27], and partial characters of serpin and cystatin from $H$. contortus were studied $[23,28,29]$. However, no information of aspin was reported in $H$. contortus. To our knowledge, in this study an aspin gene from $H$. contortus was cloned, expressed and part its biological characteristics studied for the first time.

Studies indicated that the motif "YVRDLT" would be important for the activities of aspins [30]. However, this was not well conserved in API from $H$. contortus. The motif sequence was replaced by the shortened "RDL".
Similar results were also found in other nematodes $[10,31]$. This may suggest that the "RDL" may be of crucial functional importance in inhibitory activities. It has been reported that API in different nematodes can inhibit the activity of pepsin and cathepsin E $[25,32]$. In this study, the recombinant API from $H$. contortus showed the highest inhibitory activities in pepsin digestion of hemoglobin under the optimal conditions. The recombinant API showed partial inhibitory activities at different $\mathrm{pH}$ values and different temperatures. Even when the protein was treated at $100{ }^{\circ} \mathrm{C}$, residual inhibitory activity remained (77\%). Similar results were reported in Coriolus versicolor [33]; in that study, $7 \%$ of the inhibitory activity was lost after treatment of the aspartyl protease inhibitor at $98{ }^{\circ} \mathrm{C}$. Recent studies may explain that protease inhibitors possess thermal stability were based on quantity of $\alpha$-helix and $\beta$-pleated sheet in the secondary structure of the protein [34].

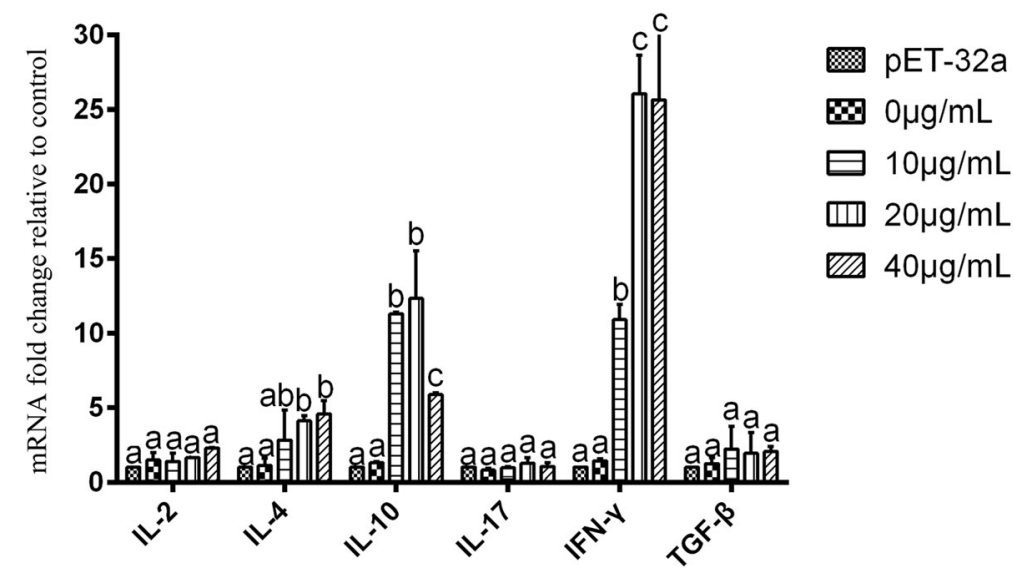

Fig. 7 Levels of multiple cytokines stimulated by the recombinant API. Goat PBMCs were incubated with the recombinant API for $12 \mathrm{~h}$, the mRNAs encoding IL-2, IL-4, IL-10, IL-17, IFN- $\gamma$ and TGF- $\beta$ were quantified by real time PCR. Different letters $(a, b$ and $c)$ above the error bars indicate significant differences $(P<0.05)$ 
The presence of aspin homologues in the free-living nematode $C$. elegans suggests that these inhibitors could function in ways that are not related to the development of parasitism by inhibiting endogenous proteases [10]. Research on O. ostertagi suggested that API played a definite role in the pre-parasitic L3 stage of the parasite [9]. In this study, it was found that the expression of API decreased significantly from free living L3 to parasitic adults. Our western blot result showed that the recombinant API could be recognized by the antiserum from goats infected with $H$. contortus. This validated that API has been secreted by the worms and induced the immune responses of the host. A deduced signal sequence found in the $\mathrm{N}$-terminal of API protein may support the idea that this protein could be secreted by the parasite. All of the results indicate that API may play important roles during the infection with $H$. contortus.

Immunohistochemical test is widely used in native antigen location and distribution in parasite research. In our study, the native API was detected on the internal surface and the gut of both adult male and female worms, thus we can consider it is an excretory secretory antigen which can secrete into host through the parasite cuticle or gut. In the early infection with $H$. contortus, complement fixation is one of the innate responses of the host immune system [35]. Delayed immunity of $H$. contortus is regulated by CD4+ T lymphocytes, IgA and IgE antibodies, eosinophil cytotoxicity and the classical complement pathway. Th2 response is a part of the humoral response associated with helminths and is characterized by the secretion of the IL-4, IL-5 and IL-10 [36, 37].

Immunosuppressive cytokine IL-10 produced by inducible $\mathrm{T}$ regulatory cells (Treg) was able to inhibit the development of allergic Th2 cell responses [38-40]. In our study, we found that recombinant API proteins could enhance goat PBMCs to produce IL-10. This means that this protein could induce the Treg cells and thus facilitate the worm infection.

IL-4 is a key regulator in humoral immunity, induces B-cell class switching to IgE and regulates MHC class II production $[41,42]$. In the present study, recombinant API increased the production of IL-4, whereas IL-2, IL17 and TGF- $\beta$ were not affected. This may indicate that this protein might be a protective antigen in the immune response against the infection with $H$. contortus.

Cytokine-regulated cellular immunity is important for host defense mechanisms, Th1 cells produce proinflammatory cytokine IFN- $\gamma$ and regulate antigen presentation and cellular immunity against infection [43-45]. In the present study, we observed the transcription of IFN- $\gamma$ was increased in PBMCs incubated with API. The results indicate that API protein might play a role in the immunization against $H$. contortus.
However, the IFN- $\gamma$ could inhibit the development of Th2 cells in the immune responses [46]. Thus, the real effects of the enhanced IFN- $\gamma$ on the resistance of the goats to $H$. contortus should be further investigated.

\section{Conclusion}

The present results indicate that API may play important roles during the infection with $H$. contortus. The western blot indicated that the recombinant API could be recognized by the antisera from goats infected with $H$. contortus. This means API has been secreted by the worms and could regulate the immune responses of the host by modulating the various cytokines. However, these results were observed from in vitro experiments; the real functions of API should be further investigated in vivo.

\section{Additional files}

Additional file 1: Table S1. Primers for amplification of AP/ gene. Table S2. Primers for real time PCR. Table S3. Primers for quantification of cytokines transcription. (DOCX $18 \mathrm{~kb}$ )

Additional file 2: Protocols. (DOCX $15 \mathrm{~kb}$ )

Additional file 3: Figure S1. Amplification efficiencies of target gene (API) and endogenous reference ( $\beta$-Tubulin) gene were verified to be similar by real time PCR. Figure S2. Amplification efficiencies of target genes $(I L-2, I L-4, I L-10, I I-17$, IFN- $\gamma$ and TGF- $\beta$ ) and endogenous reference ( $\beta$-Actin) gene were verified to be similar by real time PCR. (DOCX $57 \mathrm{~kb}$ )

\section{Abbreviations}

2D-DIGE: Two-dimensional differential gel electrophoresis; API: Aspartyl protease inhibitor; Aspin: Aspartyl protease inhibitor; Cy3: Cyanine dyes 3; DAB: Diaminobenzidine; IFN- $\gamma$ : Interferon- $\gamma$; IgG-HRP: Horseradish peroxidase labeled immunoglobulin G; IL-10: Interleukin-10; IL-17: Interleukin-17; IL2: Interleukin-2; IL-4: Interleukin-4; IPTG: Isopropyl-B-D-thiogalactopyranoside; L3: Third-stage larva; LB: Luria Bertini medium; Ni-NTA: $\mathrm{Ni}^{2+}$ - nitrilotriacetic acid; OCT: Optimal cutting temperature; PBMCs: Peripheral blood mononuclear cells; PBS: Phosphate buffered saline; SDS-PAGE: Sodium dodecyl sulfate polyacrylamide gel electrophoresis; TGF- $\beta$ : Transforming growth factor- $\beta$

\section{Acknowledgements}

We gratefully thank Yujian Wang, Xinchao Liu and Mingmin Lu, Laboratory of Veterinary Parasitology, Nanjing Agricultural University, for their valuable suggestions.

\section{Funding}

This work was funded by the National Key Basic Research Program (973 Program) of P.R. China (Grant No. 2015CB150300), the Fundamental Research Funds for the Central Universities (Grant No. KYZ201315) and the Priority Academic Program Development of Jiangsu Higher Education Institutions (PAPD).

\section{Availability of data and materials}

The datasets supporting the conclusions of this article are included within the article and its additional files. The API gene sequence of $\mathrm{H}$. contortus was submitted to GenBank under accession number KY284864.

\section{Authors' contributions}

YRF directed the project and participated in the coordination and management of the study. LBJ performed the laboratory tests and the data analysis and wrote the manuscript. JAG conducted real time PCR, GWX provided input into the experimental design. ZZC and ME obtained blood 
samples and isolated the cells. XLX, SXK and LXR provided new analytical reagents and tools. All authors read and approved the final manuscript.

\section{Competing interests}

The authors declare that they have no competing interests.

\section{Consent for publication}

Not applicable.

\section{Ethics approval and consent to participate}

All of the experimental animals used in this project were treated in strict accordance with the Animal Ethics Committee, Nanjing Agricultural University, China. All experimental protocols were approved by the Science and Technology Agency of Jiangsu Province. The approval ID is SYXK (SU) 2010-0005.

\section{Publisher's Note}

Springer Nature remains neutral with regard to jurisdictional claims in published maps and institutional affiliations.

\section{Author details}

${ }^{1}$ College of Veterinary Medicine, Nanjing Agricultural University, Nanjing 210095, People's Republic of China. '2Department of Veterinary Parasitology, Sindh Agriculture University, Tandojam, Pakistan.

\section{Received: 11 November 2016 Accepted: 11 April 2017 \\ Published online: 19 April 2017}

\section{References}

1. Alba-Hurtado F, Muñoz-Guzmán MA. Immune responses associated with resistance to haemonchosis in sheep. Biomed Res Int. 2013;2013(1):162158

2. Nikolaou S, Gasser RB. Prospects for exploring molecular developmental processes in Haemonchus contortus. Int J Parasitol. 2006;36(8):859-68.

3. White GP, Meeusen E, Newton SE. A single-chain variable region immunoglobulin library from the abomasal lymph node of sheep infected with the gastrointestinal nematode parasite Haemonchus contortus. Vet Immunol Immunopathol. 2001;78(2):117-29.

4. Bakker N, Vervelde L, Kanobana K, Knox DP, Cornelissen AWCA, Vries ED, et al Vaccination against the nematode Haemonchus contortus with a thiol-binding fraction from the excretory/secretory products (ES). Vaccine. 2004;22(5-6):618-28.

5. Mcdonald V. Parasites in the gastrointestinal tract. Parasite Immunol. 2003; 25(5):231-4

6. Emery DL, Hunt PW, Le Jambre LF. Haemonchus contortus: the then and now, and where to from here? Int J Parasitol. 2016;46(12):755-69.

7. Newton SE, Munn EA. The development of vaccines against gastrointestinal nematode parasites, particularly Haemonchus contortus. Parasitol Today. 1999:15(3):116-22.

8. Prichard R. Genetic variability following selection of Haemonchus contortus with anthelmintics. Trends Parasitol. 2001;17(9):445-53.

9. Santos MC, Xavier JK, Amarante MRV, Bassetto CC, Amarante AFT. Immune response to Haemonchus contortus and Haemonchus placei in sheep and its role on parasite specificity. Vet Parasitol. 2014;203(1-2):127-38.

10. De Maere V, Vercauteren I, Gevaert K, Vercruysse J, Claerebout E. An aspartyl protease inhibitor of Ostertagia ostertagi: molecular cloning, analysis of stage and tissue specific expression and vaccine trial. Mol Biochem Parasitol. 2005;141(1):81-8.

11. Jones SJM, Riddle DL, Pouzyrev AT, Velculescu VE, Hillier LD, Eddy SR, et al. Changes in gene expression associated with developmental arrest and longevity in Caenorhabditis elegans. Genome Res. 2001;11(8):1346-52.

12. Kageyama T. Molecular cloning, expression and characterization of an Ascaris inhibitor for pepsin and cathepsin E. Eur J Biochem. 1998;253(3):804-9.

13. Maizels RM, Blaxter ML, Scott AL. Immunological genomics of Brugia malayi: filarial genes implicated in immune evasion and protective immunity. Parasite Immunol. 2001;23(7):327-44.

14. Duffy MS, Macafee N, Burt MD, Appleton JA. An aspartyl protease inhibitor orthologue expressed by Parelaphostrongylus tenuis is immunogenic in an atypical host. Clin Diagn Lab Immunol. 2002:9(4):763-70.

15. Wang F, Xu L, Song X, Li X, Yan R. Identification of differentially expressed proteins between free-living and activated third-stage larvae of Haemonchus contortus. Vet Parasitol. 2015;215:72-7.
16. Zhao G, Yan R, Muleke Cl, Sun Y, Xu L, Li X. Vaccination of goats with DNA vaccines encoding $\mathrm{H} 11$ and IL-2 induces partial protection against Haemonchus contortus infection. Vet J. 2012;191(1):94-100.

17. Wang W, Wang S, Zhang H, Yuan C, Yan R, Song X, et al. Galectin Hco-gal-m from Haemonchus contortus modulates goat monocytes and $T$ cell function in different patterns. Parasit Vectors. 2014;7:342.

18. Yuan C, Zhang H, Wang W, Li Y, Yan R, Xu L, et al. Transmembrane protein 63A is a partner protein of Haemonchus contortus. Parasit Vectors. 2015;8:211.

19. Muleke Cl, Yan R, Sun Y, Zhao G, Xu L, Li X. Vaccination of goats against Haemonchus contortus with a recombinant cysteine protease. Small Ruminant Res. 2007;73(1):95-102

20. Zhang Z, Huang J, Li M, Sui Y, Wang S, Liu L, et al. Identification and molecular characterization of microneme 5 of Eimeria acervulina. PLoS One. 2014;9(12):e115411.

21. Bradford MM. A rapid and sensitive method for the quantitation of microgram quantities of protein utilizing the principle of protein-dye binding. Anal Biochem. 1976:72(1-2):248-54.

22. Han K, Xu L, Yan R, Song X, Li X. Molecular cloning, expression and characterization of enolase from adult Haemonchus contortus. Res Vet Sci. 2012;92(2):259-65

23. Yi D, Xu L, Yan R, Li X. Haemonchus contortus: cloning and characterization of serpin. Exp Parasitol. 2010;125(4):363-70.

24. Livak KJ, Schmittgen TD. Analysis of relative gene expression data using real-time quantitative PCR and the 2(-Delta Delta C(T)) method. Methods. 2001;25(4):402-8.

25. Abu-Erreish GM, Peanasky RJ. Pepsin inhibitors from Ascaris lumbricoides. J Biol Chem. 1974;249:1566-71.

26. Geldhof P, Claerebout E, Knox DP, Agneessens J, Vercruysse J. Proteinases released in vitro by the parasitic stages of the bovineabomasal nematode Ostertagia ostertagi. Parasitology. 2000;121(6):639-47.

27. Jolodar A, Miller DJ. Identification of a novel family of non-lysosomal aspartic proteases in nematodes. Biochim Biophys Acta. 1998;1382(1):13-6.

28. Newlands GF, Skuce PJ, Knox DP, Smith WD. Cloning and expression of cystatin, a potent cysteine protease inhibitor from the gut of Haemonchus contortus. Parasitology. 2001;122(122):371-8.

29. Yatsuda AP, Bakker N, Krijgsveld J, Knox DP, Heck AJ, De VE. Identification of secreted cysteine proteases from the parasitic nematode Haemonchus contortus detected by biotinylated inhibitors. Infect Immun. 2006;74(3): 1989-93.

30. Willenbücher J, Höfle W, Lucius R. The filarial antigens Av33/OV33-3 show striking similarities to the major pepsin inhibitor from Ascaris suum. Mol Biochem Parasitol. 1993;57(2):349-51.

31. Shaw RJ, McNeill MM, Maass DR, Hein WR, Barber TK, Wheeler M, et al. Identification and characterization of an aspartyl protease inhibitor homologue as a major allergen of Trichostrongylus colubriformis. Int J Parasitol. 2003;33:1233-43.

32. Riese RJ, Chapman HA. Cathepsins and compartmentalization in antigen presentation. Curr Opin Immunol. 2000;12(1):107-13.

33. Zhang GQ, Zhang QP, Sun Y, Tian YP, Zhou ND. Purification of a novel pepsin inhibitor from Coriolus versicolor and its biochemical properties. $J$ Food Sci. 2012:77(3):293-7.

34. Dash C, Rao M. Interactions of a novel inhibitor from an extremophilic Bacillus sp. with HIV-1 protease: implications for the mechanism of inactivation. J Biol Chem. 2001;276(4):2487-93.

35. Meeusen EN, Balic A. Do eosinophils have a role in the killing of helminth parasites? Parasitol Today. 2000;16(3):95-101.

36. Shakya KP, Miller JE, Lomax LG, Burnett DD. Evaluation of immune response to artificial infections of Haemonchus contortus in Gulf Coast Native compared with Suffolk lambs. Vet Parasitol. 2011;181(2-4):239-47.

37. Munoz-Guzman MA, Cuenca-Verde C, Valdivia-Anda G, Cuellar-Ordaz JA, Alba-Hurtado F. Differential immune response between fundic and pyloric abomasal regions upon experimental ovine infection with Haemonchus contortus. Vet Parasitol. 2012;185(2-4):175-80.

38. Levings MK, Sangregorio R, Galbiati F, Squadrone S, de Waal MR, Roncarolo MG. IFN-alpha and IL-10 induce the differentiation of human type $1 \mathrm{~T}$ regulatory cells. J Immunol. 2001;166(9):5530-9.

39. Taylor A, Verhagen J, Blaser K, Akdis M, Akdis CA. Mechanisms of immune suppression by interleukin-10 and transforming growth factor- $\beta$ : the role of T regulatory cells. Immunology. 2006;117(4):433-42.

40. Grencis RK, Humphreys NE, Bancroft AJ. Immunity to gastrointestinal nematodes: mechanisms and myths. Immunol Rev. 2014;260(1):183-205. 
41. Anthony RM, Rutitzky LI, Urban JF, Stadecker MJ, Gause WC. Protective immune mechanisms in helminth infection. Nat Rev Immunol. 2007;7(12): 975-87.

42. Moreau $\mathrm{E}$, Chauvin $\mathrm{A}$. Immunity against helminths: interactions with the host and the intercurrent infections. J Biomed Biotechnol. 2010;2010:428593.

43. Murata Y, Ohteki T, Koyasu S, Hamuro J. IFN- $\gamma$ and pro-inflammatory cytokine production by antigen-presenting cells is dictated by intracellular thiol redox status regulated by oxygen tension. Eur J Immunol. 2002;32(10): 2866-73.

44. Cope A, Le Friec G, Cardone J, Kemper C. The Th1 life cycle: molecular control of IFN-gamma to IL-10 switching. Trends Immunol. 2011;32(6):278-86.

45. Kudo M, Aosai F, Mun H-S, Norose K, Akira S, Iwakura Y, et al. The role of IFN- $\gamma$ and toll-like receptors in nephropathy induced by Toxoplasma gondii infection. Microbiol Immunol. 2004;48(8):617-28.

46. Coomes SM, Pelly VS, Kannan Y, Okoye IS, Czieso S, Entwistle L, et al. IFNy and IL-12 restrict Th2 responses during helminth/Plasmodium co-infection and promote IFNy from Th2 cells. PLoS Pathog. 2015;11(7):e1004994.

Submit your next manuscript to BioMed Central and we will help you at every step:

- We accept pre-submission inquiries

- Our selector tool helps you to find the most relevant journal

- We provide round the clock customer support

- Convenient online submission

- Thorough peer review

- Inclusion in PubMed and all major indexing services

- Maximum visibility for your research

Submit your manuscript at www.biomedcentral.com/submit 